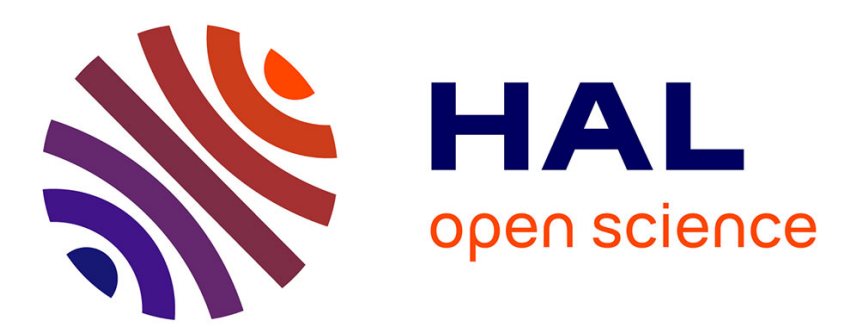

\title{
Current integration force and displacement self-sensing method for cantilevered piezoelectric actuators.
}

Ioan Alexandru Ivan, Micky Rakotondrabe, Philippe Lutz, Nicolas Chaillet

\section{To cite this version:}

Ioan Alexandru Ivan, Micky Rakotondrabe, Philippe Lutz, Nicolas Chaillet. Current integration force and displacement self-sensing method for cantilevered piezoelectric actuators.. Review of Scientific Instruments, 2009, 80 (12), 3 p. 10.1063/1.3244040 . hal-00440779

\section{HAL Id: hal-00440779 \\ https://hal.science/hal-00440779}

Submitted on 11 Dec 2009

HAL is a multi-disciplinary open access archive for the deposit and dissemination of scientific research documents, whether they are published or not. The documents may come from teaching and research institutions in France or abroad, or from public or private research centers.
L'archive ouverte pluridisciplinaire HAL, est destinée au dépôt et à la diffusion de documents scientifiques de niveau recherche, publiés ou non, émanant des établissements d'enseignement et de recherche français ou étrangers, des laboratoires publics ou privés. 


\title{
Current integration force and displacement self-sensing method for cantilevered piezoelectric actuators
}

\author{
Ioan Alexandru Ivan, Micky Rakotondrabe, ${ }^{\text {a) }}$ Philippe Lutz, and Nicolas Chaillet \\ Department of Automatic Control and Micro-Mechatronic Systems, FEMTO-ST Institute, \\ UMR CNRS 6174-UFC/ENSMM/UTBM, 24 rue Alain Savary, 25000 Besançon, France
}

(Received 29 May 2009; accepted 14 September 2009; published online 8 December 2009)

\begin{abstract}
This paper presents a new method of self-sensing both of the displacement and the external applied force at the tip of piezoelectric cantilevers. Integrated electric current across piezoelectric actuators is compensated against material nonlinearities (creep, hysteresis) to provide reliable information. We propose to compensate the hysteresis by using the Prandtl-Ishlinskii static approach while an auto regressive and moving average exogenous (ARMAX) model is used to minimize the creep influence. The quasistatic estimation, electronic circuit, and aspects related to long-term charge preservations are described or referenced. As an experiment, we tested the actuator entering in contact with a fixed force sensor. An input signal of $20 \mathrm{~V}$ peak-to-peak ( $10 \%$ of maximum range) led to force self-sensing errors inferior to $\pm 8 \%$. A final discussion about method accuracy and its limitations is made.
\end{abstract}

\section{INTRODUCTION}

Our previous work ${ }^{1}$ discussed self-sensing of free cantilever displacement. In this paper, we introduce a new algorithm based on the same electronic schematic for evaluating unknown applied force at the tip of the actuated cantilevers. Related to ${ }^{1}$ both the displacement and the applied force at the tip of the cantilevers are now observed, with the cost of a supplementary compensation of hysteresis and creep effects. The proposed approach can be adapted for long-term duration, up to several tens of seconds.

\section{DISPLACEMENT AND FORCE DETECTION}

We employ a cantilever of length $L$, width $w$, and thickness $h$. The setup is rather similar to the one already detailed in Ref. 1. Reference force was measured with a FT-S270 micromachined capacitive sensor (from FEMTO-tools company) mounted on a XYZ microtranslation table for closecontact adjustment. Reference displacement was provided by a Keyence LC-2420 optical device. Both sensors were employed as reference in identification and error evaluation tests; their presence is not needed for self-sensing method.

\section{A. Equation of the estimate force}

Theoretical charge due to applied voltage $V_{\text {in }}$ and external force $F_{\text {ext }}$ is linear

$$
\begin{aligned}
Q= & \iint_{A} \sigma d x_{1} d x_{2}=\int_{0}^{L} \int_{0}^{w}\left[-e_{31} \frac{h}{2} \frac{12 F_{\mathrm{ext}}}{Y w h^{3}}\left(L-x_{1}\right)\right. \\
& \left.+\frac{4 \varepsilon_{33} V_{\mathrm{in}}}{h}\right] d x_{2} d x_{1}=-3 e_{31} s_{11} \frac{L^{2}}{h^{2}} F_{\mathrm{ext}}+\frac{4 L w \varepsilon_{33} V_{\mathrm{in}}}{h} \\
= & \beta F_{\mathrm{ext}}+C_{P} V_{\mathrm{in}},
\end{aligned}
$$

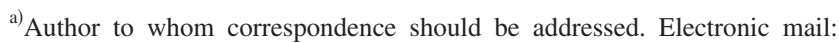
mrakoton@femto-st.fr.
}

where $\beta$ is the force sensitivity coefficient and $C_{P}$ is the actuator capacitance. $C_{R}$ is an optional reference capacitor. ${ }^{1}$

Displacement of the beam submitted to external voltage and force can be derived from ${ }^{2}$

$$
\delta=\frac{4 s_{11}^{E}}{1+\frac{d_{31}^{2}}{4 s_{11}^{E} \varepsilon_{33}^{S}}} \frac{L^{3}}{w h^{3}} F_{\text {ext }}-\frac{3 d_{31}}{1+\frac{d_{31}^{2}}{4 s_{11}^{E} \varepsilon_{33}^{S}}} \frac{L^{2}}{h^{2}} V_{\text {in }} .
$$

If we add compensation against op-amp bias current $i_{\text {BIAS }}$ and piezoelectric actuator leaking resistance $R_{F P}$ (see Ref. 1), we get the following estimated external force:

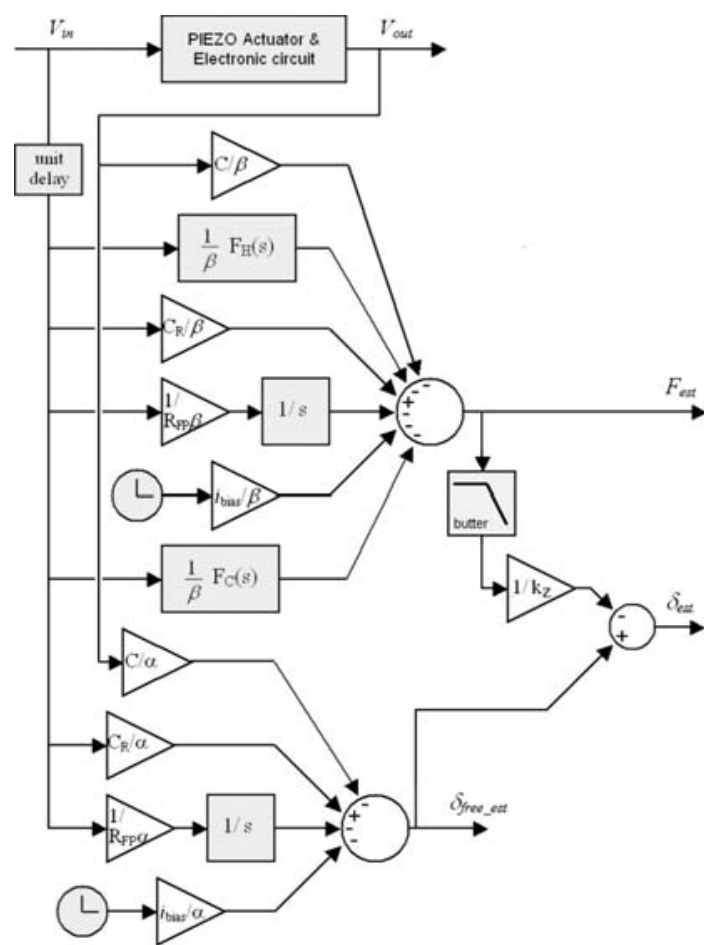

FIG. 1. Force and displacement detection model implemented under MATLAB SIMULINK. 
$F_{\text {est }}=-\frac{C}{\beta} V_{\text {out }}+\frac{C_{R}-C_{P}}{\beta} V_{\text {in }}-\frac{1}{R_{F P} \beta} \int V_{\text {in }}(t) d t-\frac{1}{\beta} \int i_{\text {BIAS }}(t) d t$.

The above expression does not take into account nonlinear nature of piezoelectric ceramics that introduce large parts of uncertainty. For instance, measurements on a unimorph beam of $15 \times 1 \times 0.2 \mathrm{~mm}^{3}$ showed $C_{P}=1.74 \mathrm{nC} / \mathrm{V}$ and $\beta$ $=1.03 \mathrm{nC} / \mathrm{mN}$. Blocking force of such a beam was only $0.07 \mathrm{mN} / \mathrm{V}$. This indicates that $1 \%$ of error (nonlinearity) in charge-to-applied voltage characteristic introduces $24 \%$ uncertainty in the estimation of force. Given that ferroelectric behavior of the PZT material shows even $15 \%$ of nonlinearity, a compensation of these unwanted effects is unavoidable.

Hence, we will replace $C_{P}$ from Eq. (3) with more appropriate estimators. Hence, final expression of the estimate force will include two additional operators for nonlinear effects: $F_{C}(s)$ for creep and $F_{H}(s)$ for hysteresis compensation

$$
\begin{aligned}
F_{\text {est }}= & -\frac{C}{\beta} V_{\text {out }}+\frac{C_{R}}{\beta} V_{\text {in }}-\frac{1}{R_{F P} \beta} \int V_{\text {in }}(t) d t \\
& -\frac{1}{\beta} \int i_{\text {BIAS }}(t) d t-\frac{1}{\beta} F_{C}(s) V_{\text {in }}-\frac{1}{\beta} F_{H}(s) V_{\text {in }} .
\end{aligned}
$$

\section{B. Equation of the estimate displacement}

Formula for free $\left(F_{\text {ext }}=0\right)$ piezoelectric beam displacement is taken from ${ }^{1}$

$\delta_{\text {free_est }}=-\frac{C}{\alpha} V_{\text {out }}+\frac{C_{R}}{\alpha} V_{\text {in }}-\frac{1}{R_{F P} \alpha} \int V_{\text {in }}(t) d t-\frac{1}{\alpha} \int i_{\text {BIAS }}(t) d t$,

where $\alpha$ is called the displacement coefficient.

When submitted to both external voltage and force, theoretical expression [Eq. (2)] is prone to nonlinearities, it is better to estimate the displacement with the following formula:

$$
\delta_{\text {est }}=\delta_{\text {free_est }}-F_{\text {est }} / k_{Z},
$$

where $k_{Z}$ is transverse mechanical stiffness of the beam.

\section{Displacement and force estimator}

The Simulink detection model of force and displacement implemented into a dSPACE real time controller sums several terms from Eqs. (4)-(6) and is shown in Fig. 1. As seen, a supplementary third-order low-pass Butterworth filter was introduced to cancel the noise of $F_{\text {est }} / k_{Z}$ term from Eq. (6) which is far superior to $\delta_{\text {free_est }}$.

\section{SELF-SENSING PARAMETER IDENTIFICATION}

Identification for only displacement self-sensing method was previously discussed in Ref. 1 . These parameters were bias current $i_{\mathrm{BIAS}}$, leaking resistance $R_{F P}$, and displacement coefficient $\alpha$. For simplicity reasons, we suppressed dielectric absorption compensation $\left(Q_{\mathrm{DA}}\right)$ but it can be reintroduced from Ref. 1 if more accuracy is required. We added a supplementary series of parameters intended for force selfsensing, such as force sensitivity $\beta$ and transverse stiffness

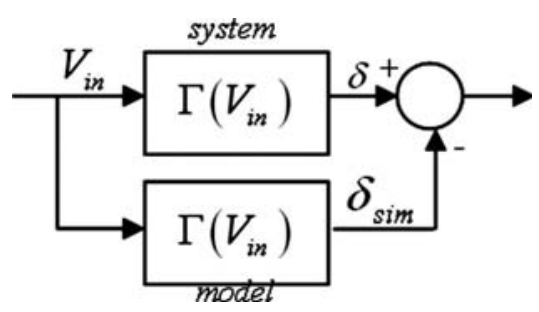

FIG. 2. Parallel compensation of nonlinear system.

$k_{Z}$ identifiable from an external force step $\left(F_{\text {ext }} \neq 0, V_{\text {in }}\right.$ $=0$ ). Also hysteresis operator $F_{H}$ and creep transfer function $F_{C}$ have to be identified. These nonlinearities characterize the piezoelectric actuator behavior between applied voltage $V_{\text {in }}$ and free actuator bending $\delta$.

To compensate the hysteresis, we use the PrandtlIshlinskii (PI) approach because of its accuracy and ease of implementation and computation (Ref. 3). The compensation is performed by putting in parallel the system and the PI model (Fig. 2). In the PI model, a hysteresis is based on the play operator, also called backlash operator. A play operator of unity slope is defined by

$$
V_{\text {out }}^{*}(t)=\max \left\{V_{\text {in }}(t)-r, \min \left[V_{\text {in }}(t)+r, V_{\text {out }}^{*}(t-T)\right]\right\},
$$

where $V_{\text {out }}^{*}$ is the output voltage compensated against bias and leaking currents and summing $-C_{R} V_{\text {in }} / C$ reference capacitor term. Parameter $r$ is the threshold and $T$ is the sampling period.

A hysteresis can be approximated by the sum of several play operators weighted by the gain (slope) $w_{i}{ }^{4}$ Let $n$ be the number of elements, so we have

$$
\begin{aligned}
V_{\text {out }}^{*}(t)= & F_{H}\left(V_{\text {in }}\right)=\sum_{i=1}^{n} w_{i} \max \left\{V_{\text {in }}(t)-r_{i}, \min \left[V_{\text {in }}(t)\right.\right. \\
& \left.\left.-r_{i}, V_{\text {out }}^{*}(t-T)\right]\right\} .
\end{aligned}
$$

We choose $n=15$ for precision and convenient complexity of the model, the parameters $b w_{i}=2 r_{i}$ and $w_{i}$ have been identified by using the steps presented in Ref. 3.

The accuracy of $F_{H}\left(V_{\text {in }}\right)$ hysteresis operator increases with the total number $n_{\text {hyst }}$ of play operators-which reasonably equals some dozens. Identification of $w_{i}$ and $r_{i}(i$ $=1, \ldots, n)$ arrays is made with a couple triangular $V_{\text {in }}$ signals of fixed slope and different amplitudes. The slope should be low enough to avoid the effect of the dynamic part on the hysteresis shape but sufficiently high to avoid the effect of the creep part. ${ }^{3}$ In our case, the slope was chosen at $\pm 20 \mathrm{~V} / \mathrm{s}$. The amplitude used for the identification is chosen to be 30 $\mathrm{V}$ peak-to-peak, which corresponds to the range use. Smaller amplitude signals are further used for identified operator error evaluation.

Creep effect is, like hysteresis, related to piezoelectric coefficients nonlinearity. The identification of the creep operator $F_{C}\left(V_{\text {in }}\right)$ is made with a linear time-invariant transfer function $^{3}$ and is performed on a ramped step input $V_{\text {in }}$ whose slope value is the same to that employed in hysteresis PI operator identification; $V_{\text {in }}=-10 \mathrm{~V}$ as in Fig. 3(a). The response is observed for a long duration of time $(\geq 200 \mathrm{~s}$ if possible). The creep part $V_{\text {creep }}(t)$ [Fig. 3(b)] is separated by subtracting the signal with already identified terms (leaking, 

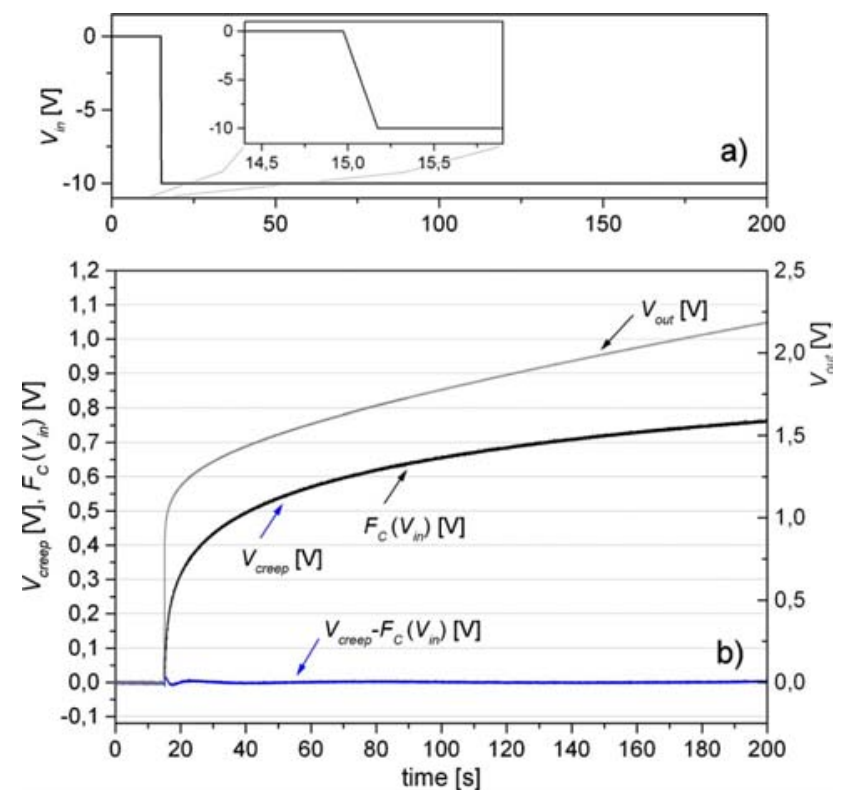

FIG. 3. (Color online) (a) Applied - $10 \mathrm{~V}$ signal for creep identification. (b) Experimental data and identified transfer function.

bias, hysteresis) and, afterwards, the model $F_{C}\left(V_{\text {in }}\right)$ is identified using the auto regressive and moving average exogenous (ARMAX) method and Matlab. It seems that from the third order, the error between the identified model and the experimental curve stops decreasing exponentially. We chose a model of fourth order

$$
F_{C}(s)=\frac{V_{\text {creep }}(s)}{V_{\text {in }}(s)}=\frac{a_{0} s^{4}+a_{1} s^{3}+a_{2} s^{2}+a_{3} s^{1}+a_{4}}{s^{4}+b_{1} s^{3}+b_{2} s^{2}+b_{3} s^{1}+b_{4}},
$$

where $a_{0}, \ldots, a_{4}$ and $b_{1}, \ldots, b_{4}$ are numerator and denominator polynomial coefficients of creep transfer function.

\section{RESULTS AND DISCUSSION}

The unimoph PZT on Ni cantilevered actuator $(15 \times 1$ $\times 0.28 \mathrm{~mm}^{3}$ ) is brought near the force sensor (close to contact). Then, a series of periodic steps [Fig. 4(a)] ranging from 0 to -10 or $-20 \mathrm{~V}$ is applied, making the actuator entering in contact and pushing the sensor. The recorded output $V_{\text {out }}$ is pictured in Fig. 4(b). As described in previous sections, $V_{\text {out }}$ and $V_{\text {in }}$ will be used to estimate the deflection and the force.
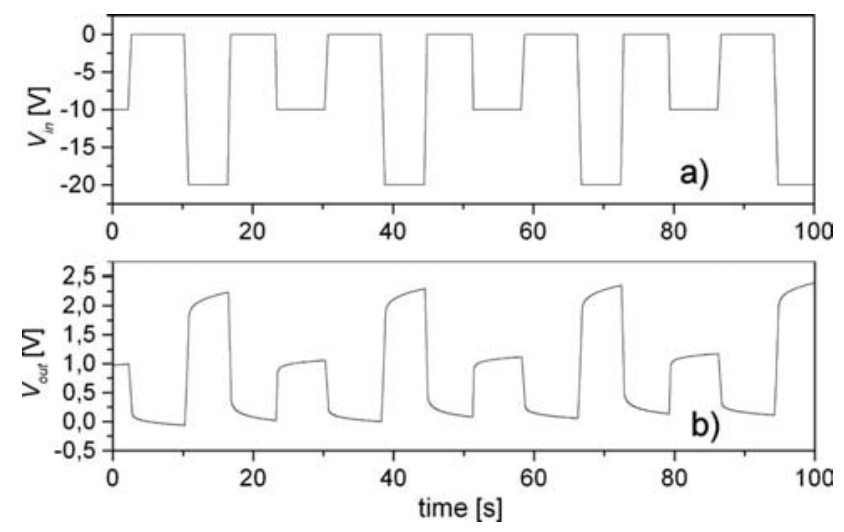

FIG. 4. (a) Arbitrary applied signal. (b) Corresponding output voltage.
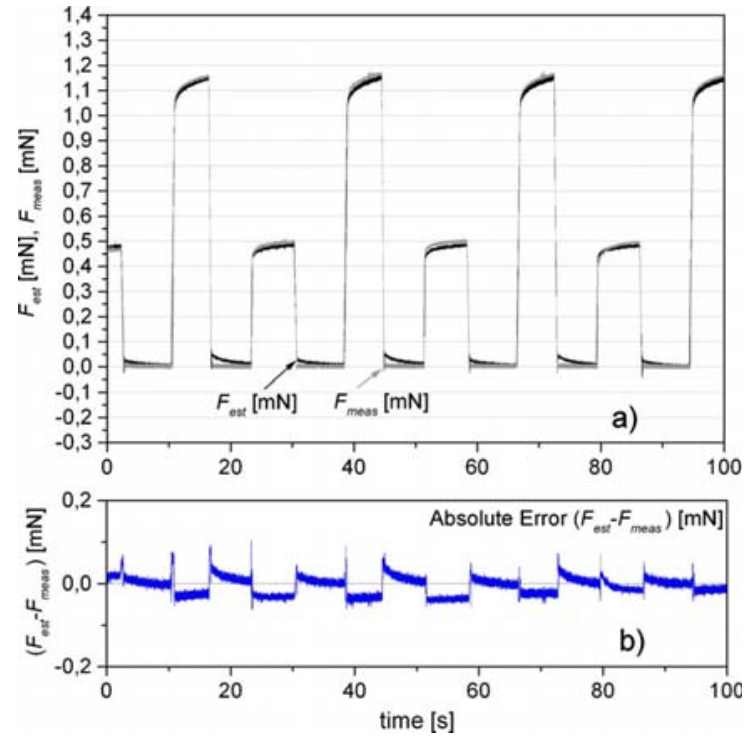

FIG. 5. (Color online) (a) Measured and estimated force. (b) Absolute error.

Maximum-recorded force was of $1.15 \mathrm{mN}$. As seen from Fig. 5 , error between estimated and measured force sums 0.16 $\mathrm{mN}$, meaning $14 \%$ (from $+8 \%$ to $-6 \%$ ).

There are some limitations in the method. Displacement performances results are, as expected, inferior to those reported in Ref. 1 but, in exchange, supplementary information about force could be provided. Also, as expected, force estimation is slightly less accurate in self-sensing actuator mode than in sensor-only mode (cantilever submitted only to external force) but the advantage of self-sensing consist in its double role: both actuator and sensing system. For instance, self-sensing method would provide useful displacement and/or force information from the arms of a microgripper.

The displacement range or dynamics of the actuator are not influenced by the self-sensing circuit, but as applied voltage increases, nonlinearities cause relative error to grow significantly, exceeding $50 \%$ for $\pm 40 \mathrm{~V}$ operation. To overcome that, more complex hysteresis operator compensation should be employed and extra close contact information would also help in ameliorating precision. Indeed, a very accurate hysteresis and creep modeling is required because $1 \%$ of error in charge estimation due to applied voltage may cause nearly a $20 \ldots 30 \%$ error in force detection.

\section{ACKNOWLEDGMENTS}

This work is supported by the E.U. FP7 SP3-People Program under Grant No. PIEF-GA-2008-219412 (New Micro-Robotic Systems featuring Piezoelectric Adaptive MicroStructures for Sensing and Actuating, with Associated Embedded Control).

${ }^{1}$ I. A. Ivan, M. Rakotondrabe, P. Lutz, and N. Chaillet, Rev. Sci. Instrum. 80, 065102 (2009).

2 J. G. Smits and W.-S. Choi, IEEE Ultrasonic Symposium, Honolulu, Hawaii, 4-7 December 1990 (IEEE, New York, 1990), pp. 1275-1278.

${ }^{3}$ M. Rakotondrabe, C. Clevy and P. Lutz, "Complete open-loop control of hysteretic, creeped and oscillating piezoelectric cantilevers," IEEE Trans. Autom. Sci. Eng. (to be published), doi:10.1109/TASE.2009.2028617.

${ }^{4}$ M. A. Krasnosel'skii and A. V. Pokrovskii, Systems with Hysteresis (Springer, Berlin, 1989), p. 410. 